\title{
Effect of olive trees density on the quality and composition of olive oil from cv. Arbequina
}

\author{
Nuno Rodrigues $^{\mathrm{a}, \mathrm{b}}$, Susana Casal ${ }^{\mathrm{c}}$, António M. Peres ${ }^{\mathrm{a}, \mathrm{d}}$, Paula Baptista ${ }^{\mathrm{a}}$, Albino Bento ${ }^{\mathrm{a}}$, \\ Hugo Martín ${ }^{\mathrm{e}}$, M. Cármen Asensio-S.-Manzanera ${ }^{\mathrm{e}}$, José Alberto Pereira ${ }^{\mathrm{a}, *}$ \\ a Centro de Investigação de Montanha (CIMO), ESA, Instituto Politécnico de Bragança, Campus de Santa Apolónia, 5300-253 Bragança, Portugal \\ ${ }^{\mathrm{b}}$ Universidad de Léon, Departamento de Ingeniería Agrária, Av. Portugal, nº 41, 24071 Léon, Spain \\ ${ }^{c}$ REQUIMTE, Laboratory of Bromatology and Hydrology, Faculty of Pharmacy, University of Porto, Rua de Jorge Viterbo Ferreira, 228, 4050-313 Porto, Portugal \\ ${ }^{\mathrm{d}}$ Laboratory of Separation and Reaction Engineering-Laboratory of Catalysis and Materials (LSRE-LCM), ESA, Instituto Politécnico de Bragança, Campus Santa Apolónia, \\ 5300-253 Bragança, Portugal \\ e Instituto Tecnológico Agrario de Castilla y León, Ctra. de Burgos Km. 119, 47071 Valladolid, Spain
}

\section{A R T I C L E I N F O}

\section{Keywords:}

Planting density

Arbequina olive oils

Quality

Chemical composition

Oxidative stability

\begin{abstract}
A B S T R A C T
The number of plants per hectare is a key factor for olive tree productivity. Nevertheless, information about the effect of tree density on olive oil quality and composition is scarce. Thus, the effect of planting densities of cv. Arbequina trees on olive oil quality and composition was studied along the first four years of production. Two types of planting tree arrangements were evaluated, namely olive trees planted at different distances within a row $(2.0 \mathrm{~m} ; 1.5 \mathrm{~m} ; 1.25 \mathrm{~m}$; and $1.0 \mathrm{~m}$, fixing the space between rows equal to $4.0 \mathrm{~m}$ ) or at different distances between rows $(4.0 \mathrm{~m} ; 3.5 \mathrm{~m}$; and $3.0 \mathrm{~m}$, fixing the space within the same row at $1.5 \mathrm{~m})$, which led to planting densities from 1250 to 2500 trees ha $^{-1}$. The results indicated that the quality parameters, composition, antioxidant activity and oxidative stability were significantly affected by the densities of plants and the crop year (Pvalue $<0.0001$, for one-way ANOVA). An increase of plants in the row and between rows showed a tendency for a slight increase of free acidity, and a reduction of the peroxide value and of the extinction specific coefficients. Fatty acid composition was also affected, with a tendency for the decrease of C16:0, C18:0, SFA and PUFA, and an increase of C18:1, C18:2 and MUFA. The antioxidant activity and the oxidative stability also showed a reduction trend. For all parameters evaluated, the crop year had a marked influence. The year of production had significant statistical effects on the evaluated parameters, which could be related to agro-climatic factors.
\end{abstract}

\section{Introduction}

World consumption of olive oil has been increasing, especially in the last decades, leading to the search of new geographical areas for olive trees plantations as well as of new production practices aiming to increase the olive oil productivity per plant or per area (Rufat et al., 2014). Traditional extensive olive groves, with few plants per hectare, are not irrigated, require high labor and maintenance, and have low yields, which results in high production costs per kilogram of olives, reducing market competitiveness of the produced olive oil (Duarte et al., 2008; Proietti et al., 2012). In contrast, high-density plantations, with high number of plants per hectare, are irrigated and intensively managed, reaching higher productivity and, although having high production costs, present lower olive oil production prices (Connor et al., 2014).
Thus, the number of high-density olive groves, with 1500-2200 trees per hectare (Rius and Lacarte, 2010), has increased significantly in non-traditional producing regions, especially in some regions of Spain (Tous et al., 2007), Italy (Godini et al., 2006), Morocco, Tunisia and in the United States of America (Berenguer et al., 2006). Nevertheless, in some regions, due to plants density and positional distribution the effective solar exposition could be a limiting factor for fruit yield. As the radiation penetrates the olive tree canopy, it is absorbed and reflected, mainly by leaves, altering light quality (Mariscal et al., 2000; Connor et al., 2014). Also, light spectral distribution is dependent on leaves density and location in the tree, influencing productivity (Bastías and Corelli-Grappadelli, 2012). Therefore, the conduction system of trees in high-density hedges and rows orientation should guaranty a good adjustment of light to achieve better productions and maximize crop management. Despite all these factors are known to influence olive

\footnotetext{
* Corresponding author

E-mail address: jpereira@ipb.pt (J.A. Pereira).
} 
grove productivity, their effect on olive oil quality and composition is still not completely understood.

The selection of olive cultivar is also a key factor in high-density olive groves. Most traditional cultivars (e.g. Cornicabra, Galega, Hojiblanca and Picual) are not well adapted to this type of high-density orchards due to their low growth rate, late fructification age and high vigor. Spanish cv. Arbequina was the first cultivar successfully adapted to high-density groves (Proietti et al., 2012; Abenoza et al., 2014). Other cultivars also showed easy adaptation, namely Arbosana and Chiquitita from Spain; Koroneiki from Greece; which, together with Arbequina, are the most widely used worldwide (Torres et al., 2009; Allalout et al., 2011; Rondanini et al., 2011; Tous et al., 2011; Bakhouche et al., 2013; Yousfi et al., 2012; Abenoza et al., 2014).

Some works have reported the study of the effect of tree density on olive tree productivity (Vossen, 2007), the physiological responses of olive trees to environmental stress (Abdallah et al., 2017), as well as the effect of irrigation deficit on photosynthesis, growth and productivity in high-density olive orchards (i.e., more than 1500 trees/ha) (HernandezSantana et al., 2017). However, the way how plant density affects olive oil quality is poorly documented. In this context, the possible effect of tree density on olive oil composition was studied, using a cv. Arbequina high-density olive grove, installed in a non-traditional olive production region in Valladolid Province (Spain). The study was conducted during four consecutive growing seasons, with four plant densities that had the same distance between rows $(4.0 \mathrm{~m})$ but different spaces between tree in each row (from $1.0 \mathrm{~m}$ to $2.0 \mathrm{~m}$ ), and three plant densities that differ in the distance between rows fixing the space of tree within the rows (Fig. 1). All olive oils were assessed taking into account the quality parameters (free acidity, peroxide value, coefficient of specific extinction, and sensory analyses), chemical composition (fatty acid composition, tocopherol profile and total phenols content), oxidative stability and antioxidant activity (DPPH, and $\mathrm{ABTS}^{+}$).

\section{Material and methods}

\subsection{Sampling}

An experimental olive grove with olive trees from Arbequina cultivar was installed in Medina de Rioseco ( $41^{\circ} 52^{\prime} 48.3^{\prime \prime} \mathrm{N} 5^{\circ} 00^{\prime} 17.9^{\prime \prime} \mathrm{W}$, $850 \mathrm{~m}$ of altitude), Valladolid Province (Spain), in May 2008. The trees were planted in rows, with different spaces within the rows (fixing the distance between rows to $4.0 \mathrm{~m}$ ), namely $4.0 \mathrm{~m} \times 2.0 \mathrm{~m}$ (planting density: 1250 trees ha $\left.^{-1}, \mathrm{~d} 1250\right), 4.0 \mathrm{~m} \times 1.5 \mathrm{~m} \quad\left(1667\right.$ trees ha $^{-1}$, d1667), $4.0 \mathrm{~m} \times 1.25 \mathrm{~m}\left(2000\right.$ trees $\left.^{-1}, \mathrm{~d} 2000\right)$, and $4.0 \mathrm{~m} \times 1.0 \mathrm{~m}$ (2500 trees $\mathrm{ha}^{-1}, \mathrm{~d} 2500$ ), and with different spaces between rows (fixing the distance between plants in the row to $1.5 \mathrm{~m}$ ), with $4.0 \mathrm{~m} \times 1.5 \mathrm{~m} \quad$ (1667 trees ha ${ }^{-1}, \quad$ d1667), $\quad 3.5 \mathrm{~m} \times 1.5 \mathrm{~m}$ (1905 trees ha $\left.{ }^{-1}, \mathrm{~d} 1905\right)$ and $3.0 \mathrm{~m} \times 1.5 \mathrm{~m}$ (2222 trees ha $\left.{ }^{-1}, \mathrm{~d} 2222\right)$ (Fig. 1). The experimental design was a completely randomized block design with three replicates. At the 2012 crop season, and during four consecutive years, for each density and at the same time (end of October or beginning of November), three independent samples of $3 \mathrm{~kg}$ each, were handpicked and immediately transported to the laboratory of the Instituto Tecnológico Agrario de Castilla y León (ITACyL), Valladolid (Spain). The fruits were extracted in a pilot extraction plant with an Abencor system (Comercial Abengoa S.A., Sevilla, Spain) with three main units: a mill, a thermobeater where malaxation takes place at controlled temperature, and a centrifuge. The yields varied from 12 to $13 \%$ ( $\mathrm{kg}$ of olive oil $/ 100 \mathrm{~kg}$ of fruits). The obtained olive oils were filtered and stored in $100 \mathrm{~mL}$ dark bottles and were analyzed within 3 months after extraction. All assays were carried out in triplicate.

\subsection{Quality parameters determination}

All samples were analyzed following the European Union standard methods (Annexes II and IX in Commission Regulation EEC/2568/91 from 11th July and amendments), being assessed the following parameters: free acidity (FA, in \% of oleic acid), peroxide values (PV, in $\mathrm{mEq} \mathrm{O}_{2} / \mathrm{kg}$ ), as well as the specific coefficients of extinction at $232 \mathrm{~nm}$
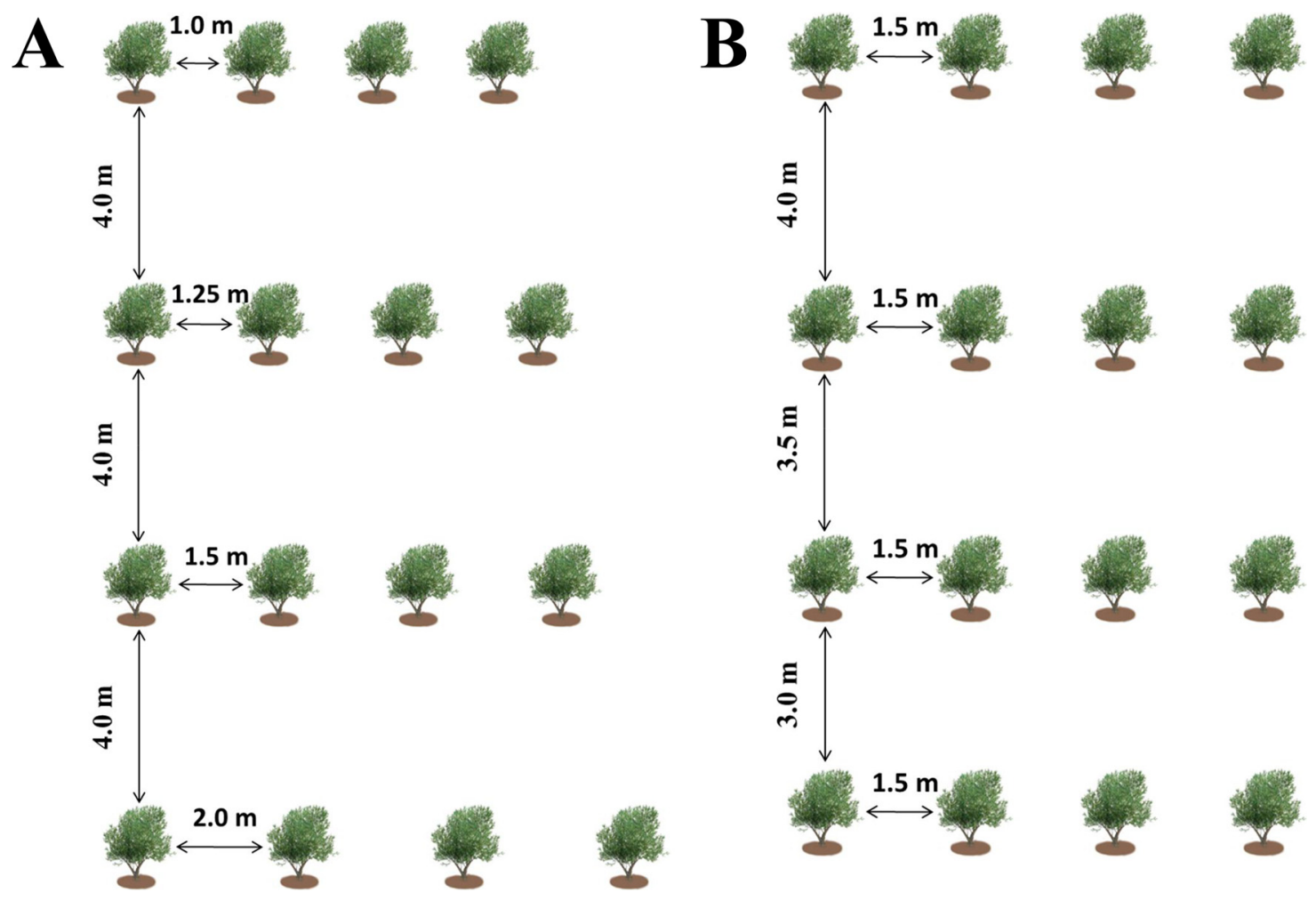

Fig. 1. Experimental design. 
and $270 \mathrm{~nm}\left(\mathrm{~K}_{232}\right.$ and $\left.\mathrm{K}_{270}\right)$ and the respective $\Delta \mathrm{K}$ values. The sensory analysis of the different olive oil samples followed the same EU Regulation and was performed by 8 trained panelists that worked or studied at the School of Agriculture of the Polytechnic Institute of Bragança (Portugal), including individuals of both sexes, 5 female and 3 male, and different ages (from 22 to 56 years). Olive oils were classified as Extra Virgin Olive Oil (EVOO) if the median of the defects was equal to 0 and the fruity positive attribute was greater than 0 ; as Virgin Olive Oil (VOO) if the median of the defects was lower than 3.5 and the fruity positive attribute was higher than 0 ; and as Lampante Olive Oil (LOO) in the other cases.

\subsection{Fatty acids composition}

Fatty acids were evaluated as their methyl esters after cold alkaline transesterification with methanolic potassium hydroxide solution (Commission Regulation EEC/2568/91 from 11th July) and extraction with n-heptane. The fatty acid profile was determined with a Chrompack CP 9001 chromatograph equipped with a split-splitless injector, a FID detector, a Chrompack CP-9050 autosampler and a $50 \mathrm{~m} \times 0.25 \mathrm{~mm}$ i.d. fused silica capillary column coated with a $0.19 \mu$ film of CP-Sil 88 (Varian). Helium was used as carrier gas at an internal pressure of $110 \mathrm{kPa}$. The temperatures of the detector and injector were $250{ }^{\circ} \mathrm{C}$ and $230{ }^{\circ} \mathrm{C}$, respectively. The split ratio was $1: 50$ and the injected volume was of $1 \mu \mathrm{L}$. The results are expressed in relative percentage of each fatty acid, calculated by internal normalization of the chromatographic peak area eluting between myristic and lignoceric methyl esters. A control sample (olive oil 47118, Supelco) and a fatty acids methyl esters standard mixture (Supelco 37 FAME Mix) were used for identification and calibration of the FID detector (Sigma, Spain).

\subsection{Tocopherols composition}

Tocopherols composition was determined according to the ISO 9936 (2006), with some modifications as described by Rodrigues et al. (2012). Tocopherols standards ( $\alpha$-, $\beta$ - and $\gamma$-) were purchase from Sigma (Spain), while the internal standard 2-methyl-2-(4,8,12-trimethyltridecyl)chroman-6-ol (tocol) was from Matreya Inc. (Pleasant Gap, PA, USA). Filtered olive oil $(50 \mathrm{mg})$ was mixed with the internal standard solution of 10 microliters of tocol from a $100 \mu \mathrm{g} / \mathrm{ml}$ solution prepared in hexane and dissolved in $\mathrm{n}$-hexane. The mixture was centrifuged for $5 \mathrm{~min}$ at 13,000 rpm and the supernatant obtained analyzed by HPLC. The liquid chromatograph consisted of a Jasco integrated system (Japan) equipped with a Jasco LC-NetII/ADC data unit, a PU1580 Intelligent Pump and a FP-920 fluorescence detector $\left(\lambda_{\text {exc }}=290 \mathrm{~nm}\right.$ and $\left.\lambda_{\text {em }}=330 \mathrm{~nm}\right)$. The chromatographic separation was achieved on a Supelcosil ${ }^{\mathrm{TM}}$ LC-SI column $(3 \mu \mathrm{m}) 75 \times 3.0 \mathrm{~mm}$ (Supelco, Bellefonte, PA), operating at $23^{\circ} \mathrm{C}$. A mixture of $\mathrm{n}$-hexane and 1,4-dioxane (97.5:2.5) was used as eluent, at a flow rate of $0.7 \mathrm{~mL} / \mathrm{min}$. Data were analyzed with the ChromNAV Control Center - JASCO Chromatography Data Station (Japan). The compounds were identified by chromatographic comparisons with authentic standards, by co-elution and by their UV spectra. Quantification was based on the internal standard method, using the fluorescence signal response and individual calibration curves for each tocopherol. Total vitamin E corresponded to the sum of the individual tocopherol masses.

\subsection{Total phenols content}

Total phenols content was assessed by the methodology described by Capannesi et al. (2000) with some modifications, as follows: $2.5 \mathrm{~g}$ of olive oil were diluted with $2.5 \mathrm{~mL}$ of $\mathrm{n}$-hexane $(1: 1 \mathrm{w} / \mathrm{v})$ and extracted three times with $2.5 \mathrm{~mL}$ of methanol/water (80:20; v/v), followed by $5 \mathrm{~min}$ of centrifugation at $5000 \mathrm{rpm}$. From the combined extract, $1 \mathrm{~mL}$ was removed, being added the same amount of Folin-Ciocalteau reagent and of $\mathrm{Na}_{2} \mathrm{CO}_{3}$ solution (7.5\%), after which $7 \mathrm{~mL}$ of purified water were added. After homogenization, the samples mixtures were stored overnight (12-16h) in the dark, and the spectrophotometric analysis was performed at $\lambda=765 \mathrm{~nm}$. A calibration curve of caffeic acid in methanol was made in concentration range of $0.04-0.18 \mathrm{mg} / \mathrm{mL}$. The final results were expressed as $\mathrm{mg}$ of caffeic acid equivalents per $\mathrm{kg}$ of olive oil (mg CAE/kg).

\subsection{Oxidative stability (Rancimat)}

The oxidative stability (OS) was measured in a Rancimat 743 apparatus (Metrohm CH, Switzerland) following the methodology previous described by Rodrigues et al. (2016). Filtered, cleaned, dried air $(20 \mathrm{~L} / \mathrm{h})$ was bubbled through the oil $(3.00 \mathrm{~g})$ heated at $120 \pm 1.6^{\circ} \mathrm{C}$, with the volatile compounds being collected in water, and the increasing water conductivity continuously measured. The time taken to reach the conductivity inflection was recorded in hours, being assumed as the OS value.

\subsection{Radical scavenging activity (RSA)}

\subsection{1. $D P P H$}

Olive oil samples were analyzed for their capacity to scavenge the stable DPPH (2,2-diphenyl-1-picrylhydrazyl) radical according to the procedure of Kalantzakis et al. (2006) with some modifications. To $1 \mathrm{~mL}$ of oil solution in ethyl acetate $(10 \%, \mathrm{w} / \mathrm{v})$ it was added $4 \mathrm{~mL}$ of a freshly prepared DPPH radical solution $\left(1 \times 10^{-4} \mathrm{M}\right.$ in ethyl acetate) in a screw-capped $15 \mathrm{~mL}$ test tube. The mixture was shaken vigorously for $10 \mathrm{~s}$ and the tube was kept in the dark for $30 \mathrm{~min}$. Absorbance was measured at $515 \mathrm{~nm}$ (Thermo Fisher Scientific, GENESYS ${ }^{\mathrm{TM}} 10$ UV-vis, USA) against a blank solution. A control sample was prepared and measured daily. The results obtained are expressed as inhibition percentage.

\subsection{2. $\mathrm{ABTS}^{+}$}

This method was performed as described by Sánchez et al. (2007), based on the capacity of a sample to inhibit the $\operatorname{ABTS}^{+}\left(2,2^{\prime}\right.$-azinobis(3ethylbenzthiazoline-6-sulfonic acid)) radical compared with a standard antioxidant reference (trolox). The $\mathrm{ABTS}^{+}$radical was generated by chemical reaction with potassium persulfate $\left(\mathrm{K}_{2} \mathrm{~S}_{2} \mathrm{O}_{8}\right)$. To $25 \mathrm{~mL}$ of $\mathrm{ABTS}^{+}(7 \mathrm{mM})$ were added $440 \mu \mathrm{L}$ of $\mathrm{K}_{2} \mathrm{~S}_{2} \mathrm{O}_{8}(140 \mathrm{mM})$, being the solution kept in darkness during $12-16 \mathrm{~h}$ at room temperature in order to form the $\mathrm{ABTS}^{+}$radical, and diluted in ethanol until an absorbance of $0.70 \pm 0.02$ at $\lambda=734 \mathrm{~nm}$. A $2 \mathrm{~mL}$ portion of the standardized ABTS .${ }^{+}$radical solution was mixed with $100 \mu \mathrm{L}$ of oil and the absorbance measured at $\lambda=734 \mathrm{~nm}$. The results obtained were expressed as inhibition percentage.

\subsection{Statistical analysis}

One-way analysis of variance (one-way ANOVA) was applied to evaluate the existence of statistical significant effects of the olive tree planting density or crop year in the composition (fatty acids, tocopherols and total phenols), quality (free acidity, peroxide values, extinction coefficients and oxidative stability) and radical scavenging activities (ABTS ${ }^{+}$and DPPH) of olive oils extracted from cv Arbequina olives produced in high density olive groves. When a statistical significant effect was detected, the pos-hoc multi-comparison Tukey's test was further used to identify the differences among olive trees planting density or crop year.

Linear multivariate classification models were used to infer about the possibility of using the composition, quality and/or radical scavenging activity data to discriminate olive tree planting densities, for each type of planting configuration evaluated (i.e., distance between olive tree planting rows fixed equal to $4.0 \mathrm{~m}$ and distance between plants in the same row varying from 1.0 to $2.0 \mathrm{~m}$; or, distance between olive tree in the same row fixed equal to $1.5 \mathrm{~m}$ and distance between 
rows ranging from 3.0 to $4.0 \mathrm{~m}$, as shown in Fig. 1). Thus linear discriminant analysis (LDA) was applied coupled with the simulated annealing (SA) meta-heuristic variable selection algorithm, which allowed identifying the minimum number of non-redundant parameters that would maximize the correct overall classification percentages (i.e., maximum model predictive sensitivities), minimizing possible noise effects (Bertsimas and Tsitsiklis, 1992; Cadima et al., 2004; Kirkpatrick et al., 1983). The predictive performances of the LDA-SA models were evaluated considering the leave-one-out cross-validation (LOO-CV) and the repeated K-fold cross-validation (repeated K-fold-CV) techniques. In the repeated $\mathrm{K}$-fold-CV, data was randomly split into $\mathrm{K}$ folds, being each of the folds left out in turn for internal-validation (predictive capability evaluation based on the sensitivity values, i.e., percentage of correct classifications) and the other K-1 folds used to train the model (i.e., to establish the best model). At the end, the $\mathrm{K}$ estimates are averaged to get the overall resampled estimate (Kirkpatrick et al., 1983). In this work the K-folds were set equal to 4, enabling the random formation of internal validation subsets with $25 \%$ of the initial data, allowing bias reduction. The procedure was repeated 10 times for putting the model under stress. The variables were scales and centered before modeling to normalize the weight of each variable in the final linear classification model. The classification performance of each LDA-SA model was graphically evaluated using 2-D or 3-D plots of the significant discriminant functions. The statistical analysis was performed using the Subselect (Cadima et al., 2004; Cadima et al., 2012; Kuhn and Johnson, 2013) and MASS (Venables and Ripley, 2002) packages of the open source statistical program R (version 2.15.1), at a 5\% significance level.

\section{Results and discussion}

\subsection{Quality parameters}

In order to evaluate the effect of different tree density on the olive oil quality, along four crop seasons (2012-2015), free acidity (FA) peroxide value (PV), extinction coefficients at 232 and $270 \mathrm{~nm}\left(\mathrm{~K}_{232}\right.$ and $K_{270}$ ) and $\Delta K$ were evaluated (for detailed results see Table 1).

The results (Table 1 ) pointed out that the FA of olive oils was significantly influenced $(P \leq 0.0001)$ by the planting tree density (independently of the spacing alignment of the trees) and by the crop year, despite the absence of a clear trend for the different crop years (2012-2015). The FA was significantly higher $(P \leq 0.05)$ for olive oils extracted from olives produced with lower space between plants in the row, although this tendency was not consistent with the decreased space between rows. Nevertheless, the mean FA values showed an overall low variation (from 0.2 to $0.3 \%$ ), allowing to be classified as EVOO, regarding the acidity, since the maximum values did not exceed the legal threshold of $0.8 \%$. The obtained results are in line with those reported for high quality olive oils from cv. Arbequina (Borges et al., 2017a; Reboredo-Rodríguez et al., 2015). The low values determined were expected, since the olive oils were obtained from fruits harvested by hand, transported to the laboratory and extracted the same day, minimizing the risk of fatty acids hydrolysis, which is the main responsible of olive oils acidity.

The PV was significantly $(P \leq 0.05)$ affected by tree density (Table 1). For 3 crop years, different spaces between plants in the row influenced the PV, being the values significantly lower $(P \leq 0.05)$ for the lowest spacing in the row (i.e., $1.0 \mathrm{~m}$ ), which corresponded to the highest tree density $\left(2500\right.$ trees ha $\left.^{-1}\right)$.

A similar trend was observed (2013 and 2015) for olive oils extracted from olives produced in tighter rows. Globally, lower PV were observed for olive oils produced from olive trees planted at different spaces within the row (from $1.2 \pm 0.4$ to $6.6 \pm 0.8 \mathrm{mEq} \mathrm{O}_{2} / \mathrm{kg}$ of olive oil) compared to the PV of olive oils obtained from olive trees planted at different spaces between rows (from $0.8 \pm 0.0$ to $7.1 \pm 0.4 \mathrm{mEq} \mathrm{O}_{2} / \mathrm{kg}$ of oil). It should remarked that all PV were lower than $20 \mathrm{mEq}_{2} / \mathrm{kg}$ olive oil, the maximum limit established by
Commission Regulation (EEC 2568/91) for olive oil classification as EVOO. The crop year also influenced this parameter $(P \leq 0.05)$, which could be probably due to different climatic conditions.

A similar trend was observed for specific extinction coefficients, with plant density influencing significantly this parameter $(P \leq 0.01)$, with the exception of three cases for $\mathrm{K}_{232}$ and one case for $\mathrm{K}_{270}$, despite the different variable patterns. In the different space between plants in the row, $K_{232}$ values decreases significantly $(P \leq 0.05)$ with plant density in 2014, while for $K_{270}$ the values of the highest density $\left(4.0 \times 1.0,2500\right.$ trees ha $\left.^{-1}\right)$ were significantly $\left(P^{<} \leq 0.05\right)$ lower than the values observed for the lowest one $\left(4.0 \times 2.0,1250\right.$ trees ha $\left.^{-1}\right)$ in three years (2013-2015). For $\mathrm{K}_{232}$, values ranged from 0.68 at density 2500 in 2015 to 1.95 at density 1250 in 2014 , and $K_{270}$ ranged from 0.08 to density 2500 in 2013 to 0.22 at density 1250 , in 2014 . The different spaces between rows also influences significantly $(P \leq 0.05)$ the specific extinction coefficients (Table 1), with the exception of one case for each study. In an half of the cases, the values obtained in the highest density were lower than the values observed in the lower ones. $\mathrm{K}_{232}$ values ranged from 0.55 at density 2222 in 2015 to 1.78 at the same density in 2012 and $K_{270}$ ranged from 0.07 for density 2222 in 2015 to 0.22 at 1250 density in 2014. Higher values were observed in 2012 and 2014, with an average of 1.42 and 1.44 for $\mathrm{K}_{232}$ and 0.16 and 0.17 for $K_{270}$ respectively, and the lower in 2013 and 2015 (Table 1), in agreement with the results observed for the PV. All values obtained in the extinction coefficient are within the legal limits established by Commission Regulation EEC/2568/91 from 11th July for the EVOO category. The obtained olive oils were subjected to sensory analysis and all were classified as EVOO without any sensory defects and with the fruity median higher than one.

\subsection{Fatty acids composition}

Olive oils are mainly constituted by triglycerides with different ratios of unsaturated and saturated fatty acids. Table 2 shows the results of the main fatty acids and the sum of saturated (SFA), monounsaturated (MUFA) and polyunsaturated fatty acids (PUFA). As expected, oleic acid (C18:1) was the major fatty acid found, varied from $77.66 \%$ to $82.93 \%$ (Table 2). With only two exceptions (years 2015 in the rows and 2013 between rows), in general, there was observed a significant effect $(P \leq 0.05)$ of the tree density on oleic acid amounts. In fact, in four situations (2012 and 2014 in the rows; and 2012 and 2015 between rows) olive oils extracted from olives produced in the highest densities were significantly richer $(P \leq 0.05)$ in oleic acid than the ones extracted from the lowest densities. The opposite situation was observed for the distance between rows in 2014 (Table 2). The crop year of production also affects significantly the proportion of oleic acid. In this work, and for cv. Arbequina olive oils, the obtained values for oleic acid are slightly higher compared to the reported by other authors, which varied from 58 to 79\% (Borges et al., 2017b; Farinelli and Tombesi, 2015; Reboredo-Rodríguez et al., 2015; Yousfi et al., 2012). This fact could be related with the environmental conditions of the region of production, namely the lower average temperature occurred during fruit growth (Ceci et al., 2017; Tena et al., 2017). Lower temperatures are known to have a positive effect on oleic acid amounts, while an increase of $1{ }^{\circ} \mathrm{C}$ degree could cause decreases of up to $2 \%$ of oleic acid amount (Rondanini et al., 2011). In general, Valladolid province is colder than the other common producing regions mentioned in the bibliography, therefore regarded as a non-traditional region. Palmitic acid (C16:0) was the second in abundance, values between 7.69 and $11.05 \%$. For this fatty acid, with the exception of the crop year 2014 in the distance of plants between rows, the distance of plants in the row and between rows as well as the crop year influenced significantly $(P \leq 0.05)$ its amount. The main observed tendency was that high densities in the row $(4.0 \times 1.0$, in 2012) and between rows $(3.0 \times 1.5$, in 2012, 2013 and 2015) showed significant $(P \leq 0.05)$ less palmitic acid than lower densities (Table 2). Linoleic acid (C18:2) was 


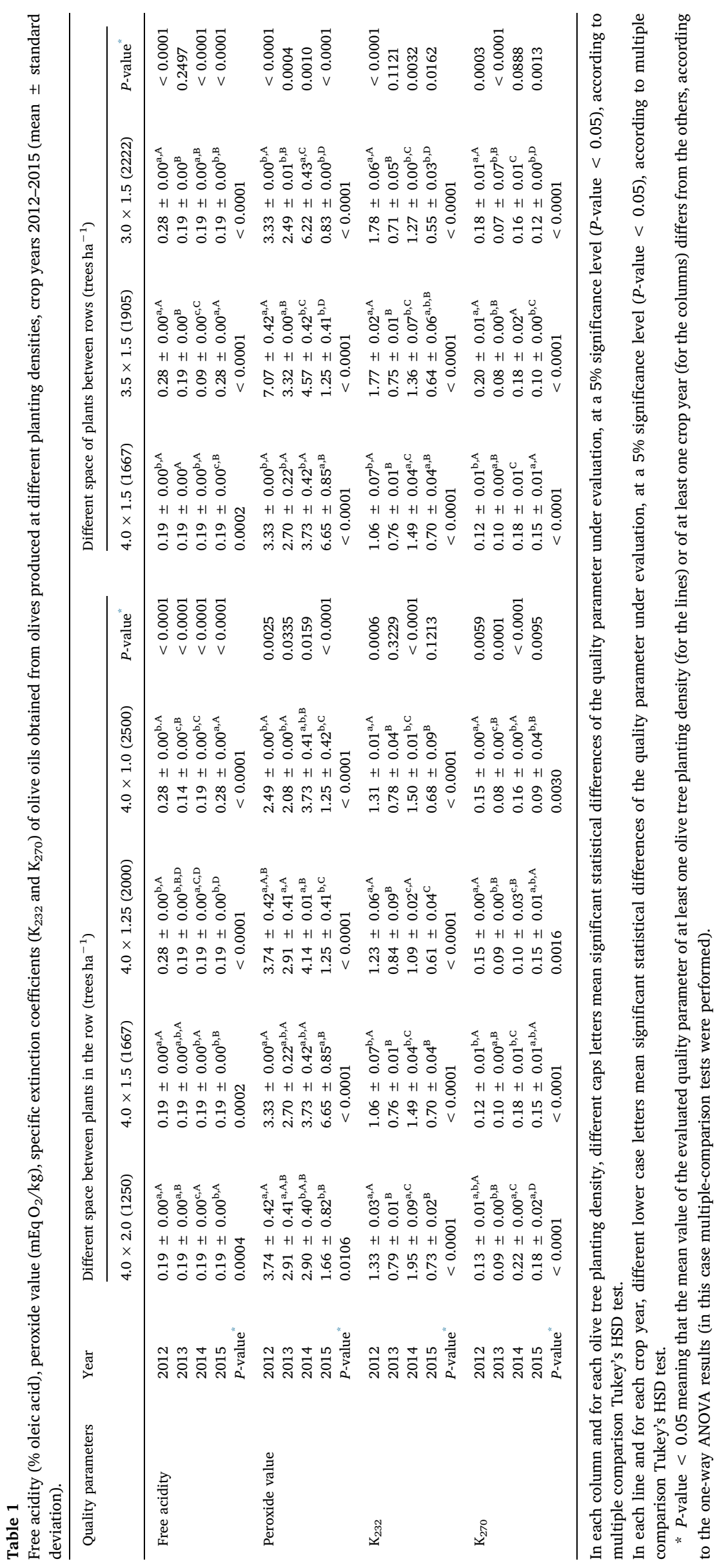




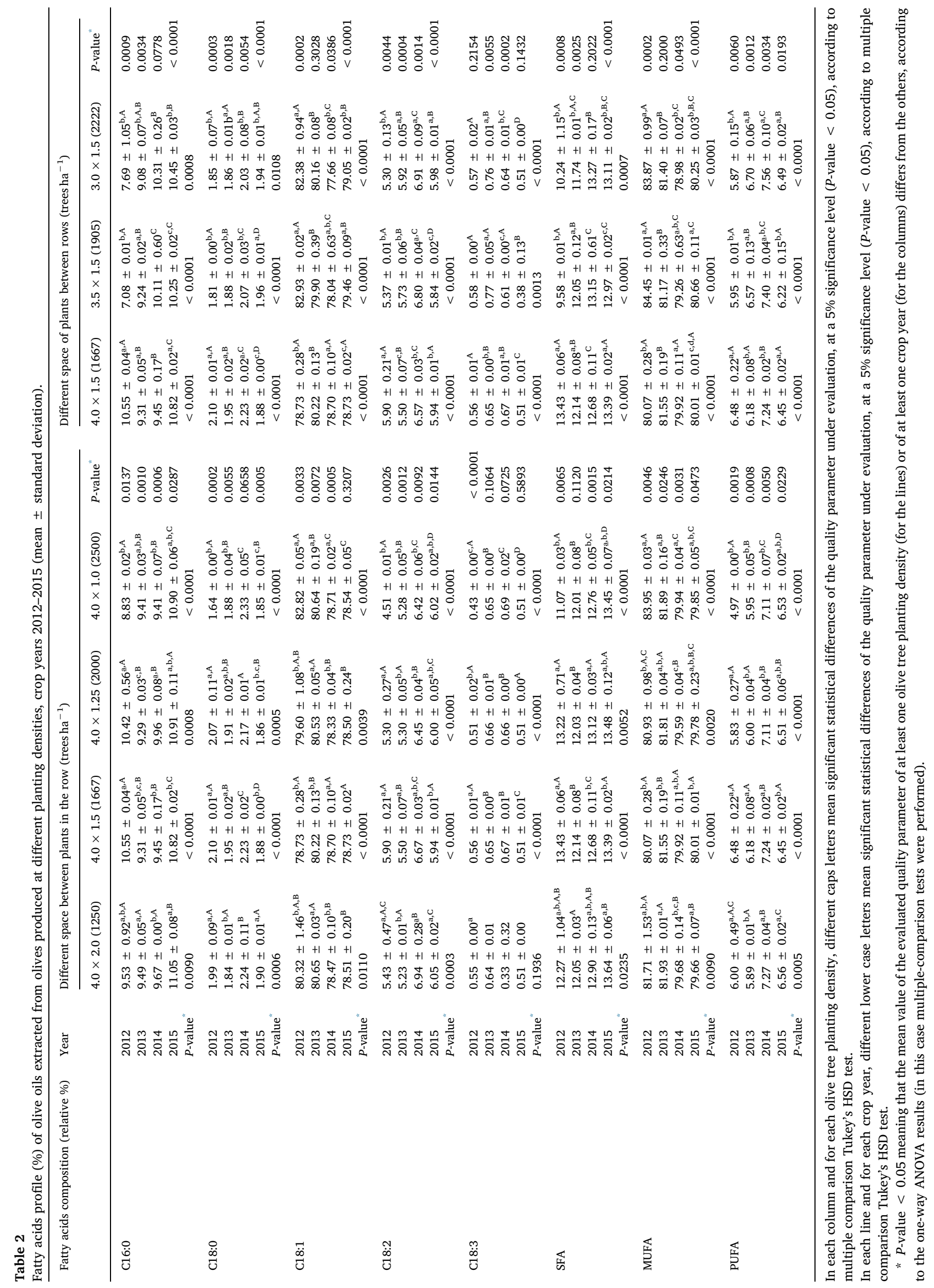


the third most abundant fatty acid, varying from 4.51 to $6.94 \%$ of the total fatty acids (Table 2). This fatty acid also showed to be significantly influenced by tree density in all years $(P \leq 0.05)$ and by the crop year $(P \leq 0.001)$, with a significant increase $\left(P^{<} \leq 0.05\right)$ with the increase of plants in the row (in 2012 and 2014) and also with the decrease of distance between rows (in 2013, 2014 and 2015). The remaining fatty acids appear in lower values and no evident effect was observed concerning the effect of plant density. The sum of SFA, MUFA and PUFA are a direct transposition of these main three fatty acids, also showing variations according the different densities and years (Table 2). The increase of number of plants in the row (in 2012 and 2014) and between rows (2012, 2013 and 2015) showed a significant $(P \leq 0.05)$ negative effect in the amounts of SFA. On the other side for MUFA, in three the observed situation (2014 for the distance in the rows, and 2012 and 2015 for the distance between rows) its amounts significantly $(P \leq 0.05)$ increase with the tree density. Whereas for PUFA, in three cases its amount significantly $(P \leq 0.05)$ decrease (2012 and 2015, distance in the rows, and 2012, distance between rows); and in two cases (2013 and 2014 in the distance between row) its amount significantly increases $(P \leq 0.05)$. The obtained results from the cv. Arbequina concerning composition and inter-annual variations of olive oils are in line with the obtained in other regions and other authors (Borges et al., 2017a, Farinelli and Tombesi, 2015; Reboredo-Rodríguez et al., 2015; Yousfi et al., 2012) taking to account the consideration mentioned above about the influence of environmental conditions.

\subsection{Tocopherols composition}

In the present work, three isoforms of tocopherols were identified and quantified in the olive oils, namely $\alpha$-, $\beta$-, and $\gamma$-tocopherol (Table 3). $\alpha$-tocopherol was the major one, representing more than $90 \%$ of the total identified as expected in olive oils. The mean values range from 206.5 to $270.9 \mathrm{mg} \mathrm{kg}^{-1}$ of oil within the spacing between plants in the row, and from 191.5 to $292.7 \mathrm{mg} \mathrm{kg}^{-1}$ of oil with spacing of plants between rows. Both distance between plants and the crop year influenced statistically the amount of tocopherols (Table 3). For $\alpha$-tocopherol, and analyzing the results of different space between plants in the row, we observed a significant decrease $(P \leq 0.05)$ on its amounts when the number of plants in the rows increases in two consecutive years. However, in 2015, an opposite tendency was observed. If the distance of plants between rows is analyzed, a significantly positive influence was observed in one year (2012) while in another year it was significantly negative (2015).

The crop year seems to be an important factor concerning $\alpha$-tocopherol amounts, in general, for all tree densities, the amounts observed in 2013 and 2015 are higher than to the registered in 2012 and 2014. Again, this is consistent with the PV and $\mathrm{K}_{232} \mathrm{~nm}$ values previously discussed, with lower tocopherol amounts for the samples with the higher oxidation degrees. $\gamma$-tocopherol was the second most representative tocopherol with mean values of 4.0 to $29.0 \mathrm{mg} \mathrm{kg}^{-1}$ of olive oil obtained with different row spacing and 3.4 to $28.0 \mathrm{mg} \mathrm{kg}^{-1}$ of olive oil in different spacing between rows. Both, distance between plants in the row and between rows, influenced significantly $(P \leq 0.05)$ the amount of $\gamma$-tocopherol, with a significant decrease in three of the analyzed situations (2012, in the row, and 2014 and 2015 between rows) and one increase (2015, in the row) according to the increase of tree density. The values obtained for $\beta$-tocopherol varied from 0.9 to $13.5 \mathrm{mg} \mathrm{kg}^{-1}$ in the row spacing and from 1.2 to $8.7 \mathrm{mg} \mathrm{kg}^{-1}$ of olive oil between rows spacing (Table 3 ). In three situations its amounts were significantly lower $(P \leq 0.05)$ in the highest densities. Also, for both, $\gamma$ tocopherol and $\beta$-tocopherol, the year of production seems to have a significant $(P \leq 0.0001)$ effect on its amounts. Contrarily to the observed for $\alpha$-tocopherol, the amounts of $\gamma$-tocopherol and $\beta$-tocopherol were in general statistically higher in 2012, but this was only observed in the first crop year. The sum of the total tocopherols follows the same tendency (Table 3), being affected by tree densities, nevertheless without a marked effect. Our results are in agreement with the obtained by other authors to the same olive cultivar (Borges et al., 2017b) and also for the inter-annual variation once the contents of $\alpha, \beta, \gamma$-tocopherols can be affected by climatic conditions, mainly temperature and rain (Aguilera et al., 2005; Beltrán et al., 2010; Dabbou et al., 2009).

\subsection{Antioxidant activity and oxidative stability}

The values of antioxidant activity for the two evaluated methods, $\mathrm{ABTS}^{+}$and DPPH, are detailed in Table 4. For the $\mathrm{ABTS}^{+}$method, the percentage of inhibition varied from $84.4 \%$ to $99.1 \%$. In 2012 , a significant $(P=0.0033)$ effect of the space between plants in the row was observed, with a decrease of inhibition with the increase of the tree density, indicative of lower antioxidant capacity. Concerning the spaces between rows, also in two years, 2013 and 2015, there was a significant effect of the density, with again with lower values at higher densities (Table 4). In the DPPH method, the results obtained showed a wider variation, between $27.5 \%$ and $95.0 \%$ of the inhibition. With the exception of 2014, spacing between plants, either in the row or between rows, had a significant effect $(P \leq 0.0001)$ on the obtained values, in both studied cases; in 2012 the values of DPPH inhibition significantly increased while in 2013 and 2015 it showed an opposite tendency. For both methodologies, the higher values of inhibition were verified in the year of 2012 and the lower in 2014. The evaluation of the total phenol content showed amounts varying from $96 \mathrm{mg} \mathrm{CAE} / \mathrm{kg}$ and $226 \mathrm{mg} \mathrm{CAE} /$ $\mathrm{kg}$ (Table 4). In the spacing between the rows, the values ranged from $91 \mathrm{mg} \mathrm{CAE} / \mathrm{kg}$ and $214 \mathrm{mg} \mathrm{CAE} / \mathrm{kg}$. In 2012 and 2013, density influenced significantly $(P \leq 0.05)$ the amount of total phenols content, with a decrease for the higher density in the row, in both years, and between rows in 2013. In 2012, an opposite tendency between rows was observed. Lower values were generally observed in 2015 and the highest in 2013, without any tendency observed on these years regarding the effect of tree density.

The oxidative stability (OS) in the present work, varied from $10.46 \mathrm{~h}$ and $22.47 \mathrm{~h}$ in row spacing and from $9.55 \mathrm{~h}$ and $25.21 \mathrm{~h}$ with spacing between the rows. There was a significant effect from both, the spacing density in the row $(P \leq 0.004)$ and between rows $(P \leq 0.0004)$, and also from the year $(P \leq 0.0001)$ (Table 4$)$. Analyzing the obtained results from the distance of plants in the row, in two years (2012 and 2014) a significant increase was observed $(P \leq 0.05)$ from the less to the highest density, while in 2013 and 2014, a significant $(P \leq 0.05)$ decrease was observed for the same densities. Considering the distance between rows, a negative effect in the OS is more pronounced, with the exception of 2012, with a significantly $(P \leq 0.05)$ decrease from the higher to the lower distance between rows (2013, 2014 and 2015). In general, the values of OS follow similar tendency to the observed by the antioxidant activity, with a significant effect $(P \leq 0.0001)$ of the production year (Table 4). According to the average values, 2014 was the year with lower values of OS, with an average of $11.5 \mathrm{~h}$, while 2012 with the highest, with an average of $20.5 \mathrm{~h}$. The OS of the olive oils is a very important parameter that could help producers to estimate the shelf life of each olive oil. Its value is influenced by different factors, as olive oil composition particularly the fatty acid profile, and also the amount of antioxidant molecules, including tocopherols and polyphenols, as well as storage conditions (Dabbou et al., 2010). In our work, depending on the years, olive oils present some differences in the fatty acid profile (Table 2) amount of tocopherols (Table 3) and total phenols (Table 4) which could influences the oxidative stability and antioxidant activity once the storage conditions of the olive oils are similar in all the four years and all analyzed within three months after extraction. For the same cultivar Borges et al. (2017a) obtained similar values of OS for olive oils from different Spanish and Brazilian regions. 


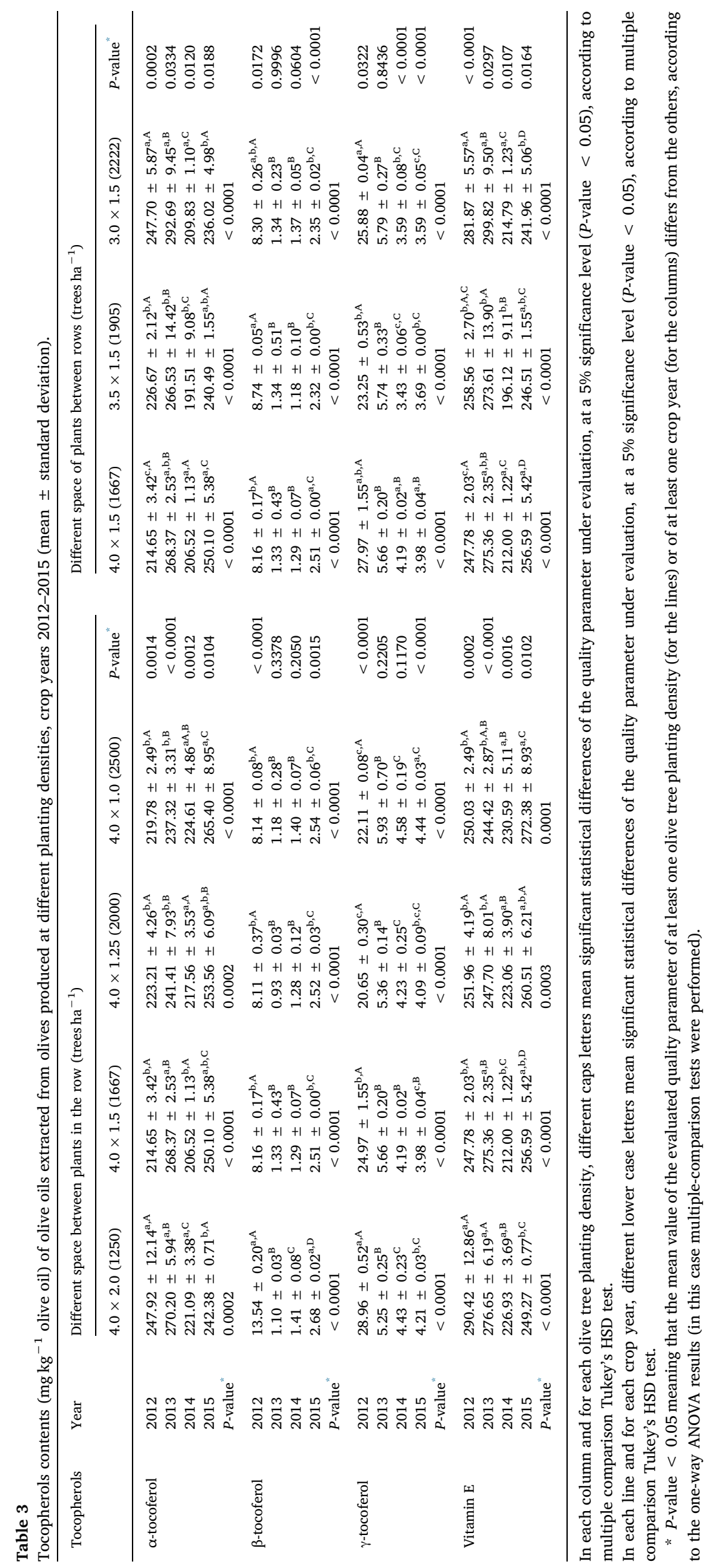




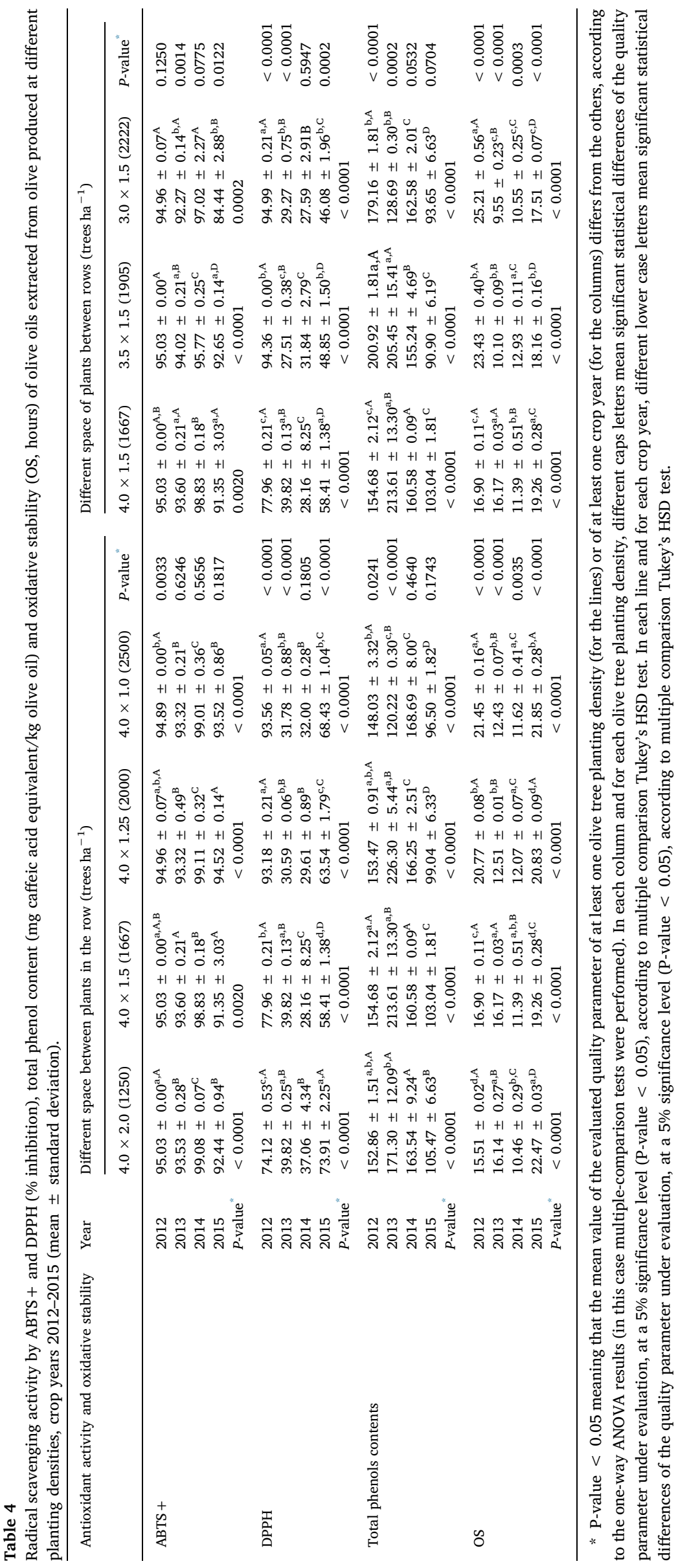


3.5. Discrimination of planting tree densities using based on the olive oils composition, quality and radical scavenging activity data

As pointed out in the previous sections, the univariate analysis showed that the planting tree density as well as the crop year had, in general, statistical significant effects on the composition, quality, radical scavenging activity and oxidative stability of the studied olive oils, although no specific and straightforward trends could be established. Thus, a multivariate approach was applied to identify which parameters could allow discriminating the olive oils according to the type of planting tree densities (i.e., olive trees planted at different distances within each row, which distanced from each other $4 \mathrm{~m}$; or, olive trees planted at $1.5 \mathrm{~m}$ distance from each other in the same row but at different distances between rows), regardless the crop year.

For the first type of planting space configuration, corresponding to a fixed $4 \mathrm{~m}$ distance between rows (Fig. 1), four planting tree densities were considered, namely, d1250 (1250 trees ha $\left.{ }^{-1}\right), \quad \mathrm{d} 1667$ (1667 trees ha $\left.{ }^{-1}\right), \quad$ d2000 (2000 trees ha ${ }^{-1}$ ) and d2500 (2500 trees ha $^{-1}$ ). A LDA-SA model, with three significant discriminant functions (explaining $72.6 \%, 15.6 \%$ and $11.8 \%$ of the data variability, respectively) was established based on the experimental data of 19 attributes, including the quality parameters (FA, $\mathrm{PV}, \mathrm{K}_{232}, \mathrm{~K}_{270}$ and $\Delta \mathrm{K}$ ), tocopherols ( $\beta$ - and $\gamma$-tocopherol), fatty acids (C16:1, C17:0, C17:1, C18:1, C18:2, C18:3, C20:0, C20:1, C22:0 and MUFA), the $\mathrm{ABTS}^{+}$and total phenols. The model allowed the correct classification of $98 \%$ of the original grouped data (Fig. 2), 88\% for the LOO-CV (6 the 48 olive oils misclassified according to the tree planting density) and $87 \pm 8 \%$ for the repeated K-fold-CV ( 4 folds $\times 10$ repeats leading to 40 randomly runs, with sensitivities ranging from $75.0 \%$ to $100 \%$ ). These results showed the accuracy of the established multivariate linear classification approach, pointing out that the 19 composition, quality and radical scavenging activity parameters could be used as chemical markers to discriminate olive oils according to the planting tree density, confirming the supposition that this agricultural production factor may indeed significantly influence the chemical composition and quality of the olive oil. Actually, from Fig. 2 it can be observed that each of the four planting tree density evaluated (d1250, d1667, d2000 and d2500) is located in a specific region of the $3 \mathrm{D}$ space described by the three linear discriminant functions (LDFs) of the LDA-SA model (d1250: negative regions of the 1 st and 2 nd LDFs plus positive region of the 3 rd LDF; d1667: positive region of the 1st LDF; d2000: negative regions of

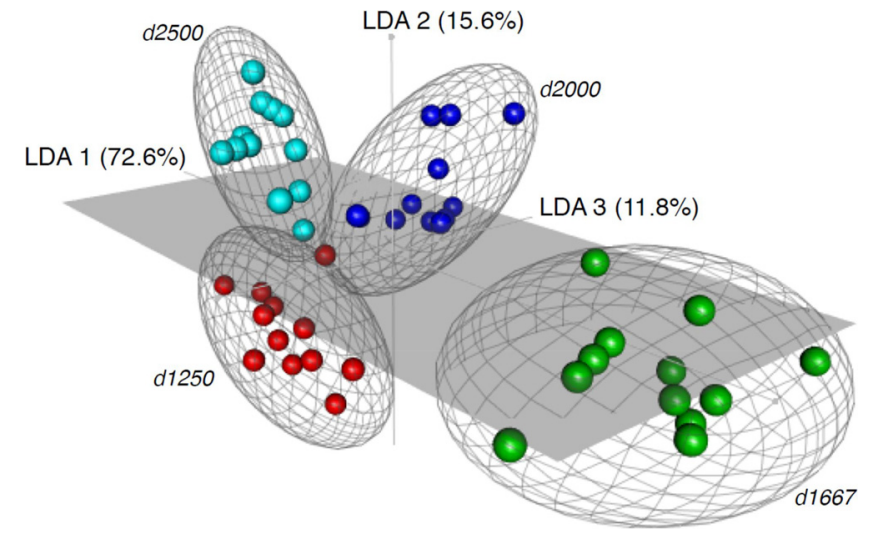

Fig. 2. Discrimination of commercial olive oils according to the olive tree planting density using a LDA-SA model with 3 linear discriminant functions, based on the olive oils contents of FA, PV, $\mathrm{K}_{232}, \mathrm{~K}_{270}, \Delta \mathrm{K}, \beta$ - and $\gamma$-tocopherols, C16:1, C17:0, C17:1, C18:1, C18:2, C18:3, C20:0, C20:1, C22:0, total MUFA, $\mathrm{ABTS}^{+}$and total phenols. Olive tree planting densities for which the distance between tree planting rows in the olive grove was set equal to $4 \mathrm{~m}$, varying the distance between trees within the same row from 1.0 to $2.0 \mathrm{~m}$ (d1250: 1250 trees ha $^{-1}$, d1667: 1667 trees ha $^{-1}$, d2000: 2000 trees ha $^{-1}$ and d2500: 2500 trees $^{-1}$ ). the 1st and 3rd LDFs; and, d2500: negative region of the 1st LDF and positive regions of the 2nd and 3rd LDFs). Thus, it could also be inferred, based on the magnitude (after scaling) and sign of the coefficients of each parameter included in the LDFs (data not shown) that: (i) $\Delta \mathrm{K}$ values contributed mostly for the discrimination of the olive oils produced from olive trees planted at a tree density of 1250 trees ha $^{-1}$; (ii) the $\mathrm{K}_{270}$ extinction coefficient values, the contents of C18:2, C18:3 and C20:0 and total MUFA had the main contribution for correctly classifying olive oils produced at a planting density of 1667 trees ha $^{-1}$; (iii) the C16:1, C17:1, C18:1, C20:1 and C22:0 contents were those that mostly contributed for correctly identifying olive oils produced from olive trees planted at a density of 2000 trees ha $^{-1}$; and finally, (iv) the fatty acids C17:0 and C18:3 gave the main contribution for assessing olive oils obtained from olives produced at a planting density of 2500 trees ha $^{-1}$. From these overall findings it could be tentatively stated that, olive oils fatty acids composition as well as the content of the quality physicochemical parameters were the mostly influenced by the panting tree density, although it was not possible to establish an enhancing or reducing effect from the density increase, which could probably be attributed to the uncontrolled crop year effect, due to the climatic effects.

Similarly, a LDA-SA model was also established to distinguish olive oils produced at different planting trees (d1667, d1905, d2222), for which the distance between trees within the same row was fixed at $1.5 \mathrm{~m}$ (varying the distance between the planting rows of the olive grove from $3 \mathrm{~m}$ to $4 \mathrm{~m}$ ). From the composition, quality, radical scavenging activity parameters evaluated for each olive oil, 15 parameters $\left(\mathrm{K}_{232}, \Delta \mathrm{K}, \mathrm{DPPH}, \Delta\right.$-tocopherol, Vitamin E, C16:0, C16:1, C17:0, C17:1, C18:2, C18:3, C20:1, C22:0, SFA and MUFA) were selected using the SA algorithm, which allowed obtaining a multivariate linear classification model with 2 significant LDFs (which explained $98.1 \%$ and $1.9 \%$ of the data variability). It should be referred that 10 of the selected parameters are common to both classification models, showing in this case, the relevant contribution of the fatty acids composition for assessing the correct planting tree density, strengthen the premise that, planting density may greatly influence the olive oils fatty acids contents. This latter LDA-SA model also showed a quite satisfactory classification performance, with sensitivities of $100 \%$ for original grouped data (Fig. 3) and 97\% for LOO-CV internal validation technique (only 1 olive oil misclassified), as well as mean sensitivities of $96 \pm 6 \%$ for the repeated K-fold-CV procedure (varying from $78 \%$ to $100 \%$ ). Finally, it could be also inferred (Fig. 3) that olive oils obtained from olive produced at tree planting density of 1667 trees ha $^{-1}$, are mainly located in the negative regions of the 1 st and 2 nd LDFs, to which greatly contribute composition on fatty acids (namely, C16:1, C17:1, C18:2, C18:3, C20:1, total SFA and MUFA). On the contrary, olive oils produced from olive groves with a tree planting density of 1905 trees ha $^{-1}$, were located in the positive region of the 1st LDF and on the negative region of the 2nd LDF, mainly due to the contents of C16:0, C17:1 and C22:0. Lastly, olive oils obtained from olive groves with a planting density of 2222 trees $\mathrm{ha}^{-1}$, were placed on the positive region of the 2nd LDF and near the origin of the $1 \mathrm{st} \mathrm{LDF}$, being the synergetic effect of $\Delta \mathrm{K}$ values, C16:0, C17:0 and C22:0 the main responsible for their discrimination. Once again, the overall contribution of the fatty acids contents towards the successful discrimination of olive oils according to the tree planting densities is unequivocally, showing that olive oil fatty acids composition is highly influenced by the olive grove planting densities.

\section{Conclusions}

With the present work it was intended to study the effect of olive plant density, with distance planting variations within the row and between rows. For that, olive oils produced from the widespread olive cultivar Arbequina were evaluated, taking into account the olive oil quality, composition and oxidative stability along the first years of production. The results allow concluding that the number of trees per 


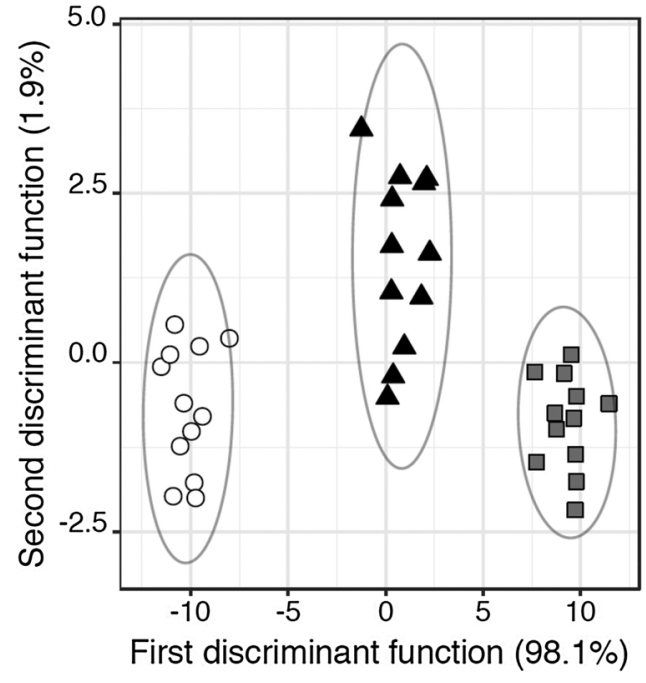

\section{O d1667 $\square$ d1905 $\Delta$ d2222}

Fig. 3. Discrimination of commercial olive oils according to the olive tree planting density using a LDA-SA model with 2 linear discriminant functions, based on the olive oils contents of $\mathrm{K}_{232}, \Delta \mathrm{K}, \mathrm{DPPH}, \alpha$-tocopherol, vitamin E, C16:0, C16:1, C17:0, C17:1, C18:2, C18:3, C20:1, C22:0, SFA and MUFA. Olive tree planting densities for which the distance between trees in the same row was set equal to $1.5 \mathrm{~m}$ and the distance between rows in the olive grove varied from 3 to $4 \mathrm{~m}$ (d1667: 1667 trees ha $^{-1}$, d1905: 1905 trees ha $^{-1}$ and d2222: 2222 trees ha ${ }^{-1}$ ).

hectare, in the first four years of production, influences the quality and composition of the obtained olive oils despite all of them could be classified as EVOO. Increasing density, both in the row and between rows, seems to exert a slight increase on FA, and a decrease in oxidative parameters (PV, $\mathrm{K}_{232}$ and $\mathrm{K}_{270}$ ). From the chemical point of view, the increase of trees per hectare led to a reduction of palmitic and oleic acids contents as well as of the total saturated and polyunsaturated fatty acids contents. On the contrary, an increase of the contents of oleic and linoleic acids was observed. Also, similar trends were observed for tocopherols, antioxidant activities and OS, which increased with density. The multivariate linear classification approach pointed out that among all the physicochemical parameters evaluated, fatty acids and quality parameters were the most influenced by the olive plant density.

Nevertheless, these conclusions may be probably very dependent of the age of the grove, as plants are still young and more fully exposed to light and nutrients. Thus, these findings although relevant must be seen as preliminary and may change when plants develop bigger canopies that will compete by light and nutrients. However, an important observation of the work was that the amounts of MUFA and mainly oleic acid were relatively high compared to the same olive cultivar cultivated in other regions of Spain and of the world, which is probably related with the climate, colder, of the region where the olive trees are grown. This information is important for the expansion of this olive cultivar for non-traditional geographical areas of production, justifying further studies.

\section{Aknowledgements}

This work was financially supported by Project POCI-01-0145FEDER-006984 (Associate Laboratory LSRE-LCM); Project UID/QUI/ 50006/2013 (REQUIMTE-LAQV); Strategic Project PEst-OE/AGR/ UI0690/2014 (CIMO), all funded by Fundo Europeu de Desenvolvimento Regional (FEDER) through COMPETE2020-Programa Operacional Competitividade e Internacionalização (POCI) and by national funds through Fundação para a Ciência e a Tecnologia (FCT), Portugal. This work was also supported by POCTEP (Programa
Cooperação Transfronteiriça Espanha-Portugal) within the project "RED/AGROTEC - Red transfronteriza España Portugal de experimentación y transferencia para el desarrollo del sector agropecuario y agroindustrial". Nuno Rodrigues thanks FCT, POPH-QREN and FSE for the Ph.D. Grant (SFRH/BD/104038/2014).

\section{References}

Abdallah, M.B., Methenni, K., Nouairi, I., Zarrouk, M., Youssef, N.B., 2017. Drought priming improves subsequent more severe drought in a drought-sensitive cultivar of olive cv. Chétoui. Sci. Horticult. 221, 43-52.

Abenoza, M., Benito, M., Oria, R., Sánchez-Gimeno, A.C., 2014. Quality characterization of the olive oil from Var. Tosca 07 grown in a commercial high density orchard. J. Am. Oil Chem. Soc. 91, 613-622.

Aguilera, M.P., Beltrán, G., Ortega, D., Fernández, A., Jiménez, A., Uceda, M., 2005. Characterisation of virgin olive oil of Italian olive cultivars: Frantoio' and Leccino', grown in Andalusia. Food Chem. 89, 387-391.

Allalout, A., Krichene, D., Methenni, K., Taamalli, A., Daoud, D., Zarrouk, M., 2011. Behavior of super-intensive Spanish and Greek olive cultivars grown in northern Tunisia. J. Food Biochem. 35, 27-43.

Bakhouche, A., Lozano-Sánchez, J., Beltrán-Debón, R., Joven, J., Segura-Carretero, A., Fernández-Gutiérrez, A., 2013. Phenolic characterization and geographical classification of commercial Arbequina extra-virgin olive oils produced in southern Catalonia. Food Res. Int. 50, 401-408.

Bastías, R.M., Corelli-Grappadelli, L., 2012. Light quality management in fruit orchards: physiological and technological prospects. Chil. J. Agric. Res. 72, 574-581.

Beltrán, G., Jiménez, A., Rio, C., Sánchez, S., Martínez, L., Uceda, M., Aguilera, M.P., 2010. Variability of vitamin $\mathrm{E}$ in virgin olive oil by agronomical and genetic factors. J. Food Compos. Anal. 23, 633-639.

Berenguer, M.J., Vossen, P.M., Grattan, S.R., Connel, J.H., Popito, V.S., 2006. Tree irrigation levels for optimum chemical and sensory properties of olive oil. HortScience 41, 427-432.

Borges, T.H., Pereira, J.A., Cabrera-Vique, C., Lara, L., Oliveira, A.F., Seiquer, I., 2017a. Characterization of Arbequina virgin olive oils produced in different regions of Brazil and Spain: physicochemical properties, oxidative stability and fatty acid profile. Food Chem. 215, 454-462.

Borges, T.H., López, L.C., Pereira, J.A., Cabrera-Vique, C., Seiquer, I., 2017b. Comparative analysis of minor bioactive constituents (CoQ10, tocopherols and phenolic compounds) in Arbequina extra virgin olive oils from Brazil and Spain. J. Food Compos. Anal. 63, 47-54.

Bertsimas, D., Tsitsiklis, J., 1992. Simulated annealing. Stat. Sci. 8, 10-15.

Cadima, J., Cerdeira, J.O., Minhoto, M., 2004. Computational aspects of algorithms for variable selection in the context of principal components. Comput. Stat. Data Anal. 47, 225-236.

Cadima, J., Cerdeira, J.O., Silva, P.D., Minhoto, M., 2012. The subselect R package. http://cran.rproject.org/web/packages/subselect/vignettes/subselect.pdf . Accessed $15 / 02 / 2016$.

Capannesi, C., Palchetti, I., Mascini, M., 2000. Electrochemical sensor and biosensor for polyphenols detection in olive oils. Food Chem. 71, 553-562.

Ceci, L.N., Mattar, S.B., Carelli, A.A., 2017. Chemical quality and oxidative stability of extra virgin olive oils from San Juan province (Argentina). Food Res. Int. 100, 764-770.

Connor, D.J., Gómez-del-Campo, M., Rousseaux, M.C., Searles, P.S., 2014. Structure, management and productivity of hedgerow olive orchards: a review. Sci. Hortic. 169, 71-93.

Dabbou, S., Brahmi, F., Taamali, A., Issaoui, M., Ouni, Y., Braham, M., Hammami, M., 2010. Extra virgin olive oil components and oxidative stability from olives grown in Tunisia. J. Am. Oil Chem. Soc. 87, 1199-1209.

Dabbou, S., Issaoui, M., Esposto, S., Sifi, S., Taticchi, A., Servili, M., Hammami, M., 2009. Cultivar and growing area effects on minor compounds of olive oil from autochthonous and European introduced cultivars in Tunisia. J. Sci. Food Agric. 89, 1314-1325.

Duarte, F., Jones, N., Fleskens, L., 2008. Traditional olive orchards on sloping land: sustainability or abandonment? J. Environ. Manage. 89, 86-98.

Farinelli, D., Tombesi, S., 2015. Performance and oil quality of 'Arbequina' and four Italian olive cultivars under super high density hedgerow planting system cultivated in central Italy. Sci. Hortic. 192, 97-107.

Godini, A., Palasciano, M., Ferrara, G., Camposeo, S., 2006. Prime osservazioni sul comportamento agronomico di cultivar di olivo allevate con il modello superintensivo. Frutticoltura 3, 40-44.

Hernandez-Santana, V., Fernández, J.E., Cuevas, M.V., Perez-Martin, A., Diaz-Espejo, A., 2017. Photosynthetic limitations by water deficit: effect on fruit and olive oil yield, leaf area and trunk diameter and its potential use to control vegetative growth of super-high density olive orchards. Agric. Water Manage. 184, 9-18.

ISO 9936, 2006. Animal and Vegetable Fats and Oils - Determination of Tocopherol and Tocotrienol Contents by High-Performance Liquid Chromatography.

Kalantzakis, G., Blekas, G., Pegklidou, K., Boskou, D., 2006. Stability and radicalscavenging activity of heated olive oil and other vegetable oils. Eur. J. Lipid Sci. Technol. 108, 329-335.

Kirkpatrick, S., Gelatt, C.D., Vecchi, M.P., 1983. Optimization by simulated annealing Science 220, 671-680.

Kuhn, M., Johnson, K., 2013. Applied Predictive Modeling. Springer Science Business Media, New York. 
Mariscal, M.J., Orgaz, F., Villalobos, F.J., 2000. Modelling and measurement of radiation interception by olive canopies. Agric. For. Meteorol. 100, 183-197.

Proietti, P., Nasini, L., Ilarioni, L., 2012. Photosynthetic behavior of Spanish Arbequina and Italian Maurino olive (Olea europaea L.) cultivars under super-intensive grove conditions. Photosynthetica 50, 239-246.

Reboredo-Rodríguez, P., González-Barreiro, C., Cancho-Grande, B., Fregapane, G., Salvador, M.D., Simal-Gándara, J., 2015. Characterisation of extra virgin olive oils from Galician autochthonous varieties and their co-crushings with Arbequina and Picual cv. Food Chem. 176, 493-503.

Rius, X., Lacarte, J.M., 2010. La revolución del Olivar. El Cultivo en Seto. Comgrafic S.A., Barcelona.

Rodrigues, N., Dias, L.G., Veloso, A.C.A., Pereira, J.A., Peres, A.M., 2016. Evaluation of extra-virgin olive oils shelf life using an electronic tongue-chemometric approach. Eur. Food Res. Technol. 243, 597-607.

Rodrigues, N., Malheiro, R., Casal, S., Asensio-S-Manzanera, M.C., Bento, A., Pereira, J.A., 2012. Influence of spike lavender (Lavandula latifolia Med.) essential oil in the quality, stability and composition of soybean oil during microwave heating. Food Chem. Toxicol. 50, 2894-2901.

Rondanini, D.P., Castro, D.N., Searles, P.S., Rousseaux, M.C., 2011. Fatty acid profiles of varietal virgin olive oils (Olea europaea L.) from mature orchards in warm arid valleys of Northwestern Argentina (La Rioja). Grasas y Aceites 62, 399-409.

Rufat, J., Villar, J.M., Pascual, M., Falguera, V., Arbones, A., 2014. Productive and vegetative response to different irrigation and fertilization strategies of an Arbequina olive orchard grown under super-intensive conditions. Agric. Water Manage. 144, 33-41.

Sánchez, C.S., González, A.M.T., García-Parrilla, M.C., Granados, J.J.Q., Serrana, H.L.G., Martínez, M.C.L., 2007. Different radical scavenging tests in virgin olive oil and their relation to the total phenol content. Anal. Chim. Acta 593, 103-107.

Tena, N., Aparicio, R., García-González, D.L., 2017. Virgin olive oil stability study by mesh cell-FTIR spectroscopy. Talanta 167, 453-461.

Torres, M.M., Pierantozzi, P., Cáceres, M.E., Lambombarda, P., Fontanazza, G., Maestri, D.M., 2009. Genetic and chemical assessment of Arbequina olive cultivar grown in Córdoba province, Argentina. J. Sci. Food Agric. 89, 523-530.

Tous, J., Romero, A., Hermoso, J.F., Ninot, A., 2011. Mediterranean clonal selections evaluated for modern hedgerow olive oil production in Spain. Calif. Agric. 65, 34-38.

Tous, J., Romero, A., Plana, J., Hermoso, J.F., 2007. Olive oil cultivars suitable for veryhigh density planting conditions. Acta Horticult. 791, 403-408.

Venables, W.N., Ripley, B.D., 2002. Modern Applied Statistics with S (Statistics and Computing), 4th edn. Springer, New York.

Vossen, P., 2007. Olive oil: history, production, and characteristics of the world's classic oils. HortScience 42, 1093-1100.

Yousfi, K., Weiland, C.M., García, J.M., 2012. Effect of harvesting system and fruit cold storage on virgin olive oil chemical composition and quality of superintensive cultivated 'Arbequina' olives. J. Agric. Food. Chem. 60, 4743-4750. 